\title{
Short Term Predicting Volatility Service Jordanian Sector
}

\author{
S. Al Wadi ${ }^{1}$, Ola Basbous ${ }^{2}$ \\ 1. Department of Finance, Faculty of Business, The University of Jordan, Jordan. \\ E-mail: Sadam_alwadi@yahoo.co.uk \\ 2. MBA researcher, E-mail: ola-alsham@hotmail.com
}

\begin{abstract}
Stock market volatility have added an important section in risk scholarship and it is actual problem particularly in emerging markets. Earlier, it is measured by standard deviation of the return. Consequently, in this research the volatility data will be predicted based on ARIMA model (Autoregressive Integrated Moving Average model) of the service sector in Amman Stock Exchange (ASE) from January 2019 to December 2019. Consequently this article shows that the ARIMA model has important results in prediction. Therefore, These outcomes will be helpful for the investments.
\end{abstract}

Keywords: ARIMA model, forecasting, Service sector.

DOI: $10.7176 / \mathrm{EJBM} / 11-36-14$

Publication date: December $31^{\text {st }} 2019$

\section{Introduction}

Volatility is important point for many scholars in financial institutions specially in emerging markets. Therefore, numerous scholars have focus in this field such as detecting and modeling and forecasting volatility since the volatility is used to assess the risk in the market for more details refer to (Bollersley, et al. 2016). Newly, many models of volatility have been recommend in order to make testing of the major trade-off between return and risk of financial assets such as GARCH model. This model is implemented for modeling and predicting volatility data (Babu \& Reddy, 2015).

As we stated before, several scientists have focused on the volatility data since all the financial data are extremely volatile. Therefore, the data trend and accuracy stores can be happened simultaneously (Babu \& Reddy, 2015). Consequently, this reason encourage the researchers to expand many approaches for modeling the forecasting volatility data. (Joukar \& Nahmens, 2015) employed ARCH and GARCH models to calculate the volatility. The mathematical definition of volatility can be defined (Al Wadi, 2017). The volatility data hardly forecasting since the data are non-stationary and non-linear with high heteroscedasticity [Wang, et. al., 2012]. This reason encourage the scientists to recover many predicting models such as artificial neural network model, ARIMA model and others. ARIMA model is an traditional model with widely application in stock market data application [Awajan, et. al., 2017, Awajan, et. al., 2017, Al Wadi, 2013].

thousands of articles have available using ARIMA model in many fields. Therefore, in order to highpoint the gap and the differences between this work and previous works the a critically review should be presented. Numerous scientists have been emerging predicting models such as exponential, regression, GARCH models. However, only some linked works that has used ARIMA model in predicting financial data such as [Khashei, et. al., 2012; Wang, 2011; Al-Khazaleh et al, 2015]. Whereas, rarely to find any article that utilize Amman Stock Exchange using ARIMA model in forecasting such as (Al Wadi, 2015; Al Wadi, 2017; Al Wadi, et al., 2011). Especially the volatility of service sector in ASE recently.

\section{Autoregressive Integrated Moving-Average Model (ARIMA (p,d,q))}

The auto-regressive moving average is signified by (ARMA) model is implemented for stationary data only, it contains three combination models. An addition of the ordinary ARMA model is the auto-regressive integrated moving-average model (ARIMA $(p, d, q))$ given by : 


$$
\phi_{\mathrm{p}}(\mathrm{B})(1-\mathrm{B})^{\mathrm{d}} \mathrm{Y}_{\mathrm{t}}=\grave{\mathrm{e}}_{0}+\grave{\mathrm{e}}_{\mathrm{q}}(\mathrm{B}) \mathrm{e}_{\mathrm{t}}
$$

Where $\mathrm{p}, \mathrm{d}$ and $\mathrm{q}$ denote orders of auto-regression, integration (differencing) and moving average, respectively. When $d=0$, the ARIMA model reduces to the ordinary ARMA model [Awajan, et. al., 2017].

\section{Result and discussion}

MINTAB software is applied to create the results. The daily service data from ASE for a specific period of time has been designated as the statistical population. There are many ARIMA model can be predictable for one column of dataset based on using different values of $\mathrm{p}, \mathrm{d}$ and $\mathrm{q}$. Therefore, the fitted ARIMA model which has less MSE (Mean Square Error) which is ARIMA $(1,1,0)$

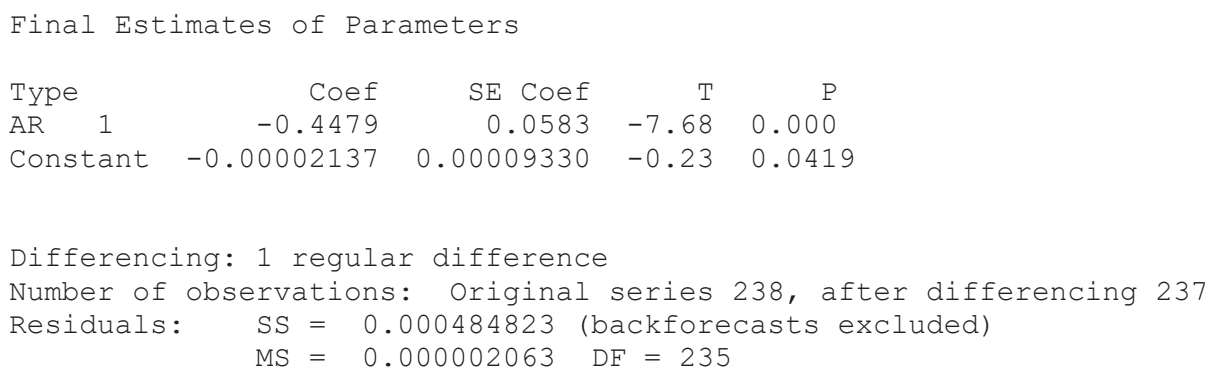

It is noticeable here is that MS is very small which indicate that the forecasting accuracy is very high.

$\begin{array}{lrrrr}\text { Modified Box-Pierce } & \text { (Ljung-Box) } & \text { Chi-Squ } \\ \text { Lag } & 12 & 24 & 36 & 48 \\ \text { Chi-Square } & 47.0 & 68.6 & 83.5 & 105.5 \\ \text { DF } & 10 & 22 & 34 & 46 \\ \text { P-Value } & 0.000 & 0.000 & 0.000 & 0.000\end{array}$

Also here the P-value is significant at all the lages since it is less than 0.05 . Therefore, the predicted 50 values (next 50 days) is

$\begin{array}{rccc}\text { Forecasts from period } 238 & \\ & & & \\ \text { Period } & \text { Forecast } & \text { Percent } & \text { Limits } \\ 239 & 0.0010440 & -0.0017718 & 0.0038598 \\ 240 & 0.0008769 & -0.0023395 & 0.0040933 \\ 241 & 0.0009304 & -0.0029216 & 0.0047823 \\ 242 & 0.0008851 & -0.0033953 & 0.0051654 \\ 243 & 0.0008840 & -0.0038320 & 0.0056000 \\ 244 & 0.0008631 & -0.0042322 & 0.0059584 \\ 245 & 0.0008511 & -0.0046052 & 0.0063074 \\ 246 & 0.0008351 & -0.0049564 & 0.0066266 \\ 247 & 0.0008209 & -0.0052888 & 0.0069306 \\ 248 & 0.0008059 & -0.0056057 & 0.0072175 \\ 249 & 0.0007912 & -0.0059088 & 0.0074913 \\ 250 & 0.0007764 & -0.0062001 & 0.0077530 \\ 251 & 0.0007617 & -0.0064809 & 0.0080043 \\ 252 & 0.0007469 & -0.0067522 & 0.0082461 \\ 253 & 0.0007322 & -0.0070150 & 0.0084794 \\ 254 & 0.0007174 & -0.0072701 & 0.0087050 \\ 255 & 0.0007027 & -0.0075182 & 0.0089235 \\ 256 & 0.0006879 & -0.0077599 & 0.0091357 \\ 257 & 0.0006731 & -0.0079956 & 0.0093419 \\ 258 & 0.0006584 & -0.0082258 & 0.0095426 \\ 259 & 0.0006436 & -0.0084509 & 0.0097382 \\ 260 & 0.0006289 & -0.0086713 & 0.0099290 \\ 261 & 0.0006141 & -0.0088872 & 0.0101154 \\ 262 & 0.0005994 & -0.0090989 & 0.0102976 \\ & & & \end{array}$




$\begin{array}{llll}263 & 0.0005846 & -0.0093067 & 0.0104759 \\ 264 & 0.0005698 & -0.0095109 & 0.0106505 \\ 265 & 0.0005551 & -0.0097115 & 0.0108217 \\ 266 & 0.0005403 & -0.0099088 & 0.0109895 \\ 267 & 0.0005256 & -0.0101030 & 0.0111541 \\ 268 & 0.0005108 & -0.0102942 & 0.0113158 \\ 269 & 0.0004960 & -0.0104826 & 0.0114747 \\ 270 & 0.0004813 & -0.0106683 & 0.0116308 \\ 271 & 0.0004665 & -0.0108513 & 0.0117844 \\ 272 & 0.0004518 & -0.0110320 & 0.0119355 \\ 273 & 0.0004370 & -0.0112102 & 0.0120843 \\ 274 & 0.0004223 & -0.0113862 & 0.0122307 \\ 275 & 0.0004075 & -0.0115601 & 0.0123750 \\ 276 & 0.0003927 & -0.0117318 & 0.0125173 \\ 277 & 0.0003780 & -0.0119015 & 0.0126575 \\ 278 & 0.0003632 & -0.0120693 & 0.0127958 \\ 279 & 0.0003485 & -0.0122353 & 0.0129322 \\ 280 & 0.0003337 & -0.0123994 & 0.0130668 \\ 281 & 0.0003189 & -0.0125618 & 0.0131997 \\ 282 & 0.0003042 & -0.0127226 & 0.0133309 \\ 283 & 0.0002894 & -0.0128817 & 0.0134605 \\ 284 & 0.0002747 & -0.0130392 & 0.0135886 \\ 285 & 0.0002599 & -0.0131953 & 0.0137151 \\ 286 & 0.0002452 & -0.0133498 & 0.0138402 \\ 287 & 0.0002304 & -0.0135030 & 0.0139638 \\ 288 & 0.0002156 & -0.0136548 & 0.0140860\end{array}$

\section{Conclusion}

This article presented a important model that carries a good predicting model of the new high technology procedure. Consequently, collecting enough data to predict service data in ASE, an ARIMA model are applied over the dataset performed to improve the prediction.. Around 250 observations were collected to appliance the forecasts of this and the best ARIMA model were selected based on the most famous criteria which is MSE (Mean Square Error). Then the 50 future values will be presented. Forthcoming research in this topic includes other stock market data such as industrial data also the future values can be found using the suggested model.

\section{References}

Al-Khazaleh, Ahmad MH, S. Al Wadi, and Faisal Ababneh. ( 2015) ."Wavelet transform asymmetric winsorized mean in detecting outlier values". Far East Journal of Mathematical Sciences . 96.3: 339-351.

Al Wadi, S., Abdulkareem Hamarsheh, and Hazem Alwadi. (2013). "Maximum overlapping discrete wavelet transform in forecasting banking sector." Applied Mathematical Sciences. 7.80 : 3995-4002.

Alwadi, S., (2015). Forecasting Short Term Financial Data. European Scientific Journal 11, No.25. 251 -255.

Al Wadi, S. (2017). Improving volatility risk forecasting accuracy in industry sector. International Journal of Mathematics and Mathematical Sciences, 2017.

Al Wadi, S., Ismail, M. T., \& Abdul Kari, S. A. (2011). Discovering Structure breaks in Amman stocks market. Journal of Applied Sciences, 11, 1273-1278.

Awajan, Ahmad M., Mohd Tahir Ismail, \& Al Wadi. (2017). "A Hybrid Approach EMD-MA For Short-Term Forecasting Of Daily Stock Market Time Series Data. Journal Of Internet Banking And Commerce 22.1.

Awajan, A. M., Ismail, M. T., \& Al Wadi, S. (2017). A hybrid emd-ma for forecasting stock market index. Italian Journal of Pure and Applied Mathematics, 38(1), 1-20.

Awajan, A. M., Ismail, M. T., \& Wadi, S. A. (2017). Forecasting time series using EMD-HW bagging. International Journal of Statistics \& Economics ${ }^{\mathrm{TM}}$, 18(3), 9-21.

Bollerslev, T., Patton, A., \& Quaedvlieg, R., (2016), Exploiting the errors: A simple approach for improved 
volatility forecasting, Journal of Econometrics, 192, 1- 18.

Babu, C. N., \& Reddy, B. E. (2015). Prediction of selected Indian stock using a partitioning-interpolation based ARIMA-GARCH model. Applied Computing and Informatics, 11(2), 130-143.

Joukar, A., \& Nahmens, I. (2015). Volatility forecast of construction cost index using general autoregressive conditional heteroskedastic method. Journal of construction engineering and management, 142(1), 04015051 .

Khashei, M., Bijari, M., \& Ardali, G. A. R. (2012). Hybridization of autoregressive integrated moving average (ARIMA) with probabilistic neural networks (PNNs). Computers \& Industrial Engineering, 63(1), 37-45.

Wang, J. J., Wang, J. Z., Zhang, Z. G., \& Guo, S. P. (2012). Stock index forecasting based on a hybrid model. Omega, 40(6), 758-766. 